\title{
Career Decision Making Self-Efficacy Mediator Antara Dukungan Kontekstual dan Adaptabilitas Karier
}

\author{
Shavira Alissa \\ Psikologi, Universitas YARSI Jakarta, Indonesia \\ Email: sari.zakiah@yarsi.ac.id \\ Sari Zakiah Akmal \\ Psikologi, Universitas YARSI Jakarta, Indonesia \\ Email: sari.zakiah@yarsi.ac.id
}

(Diterima: 07-Oktober-2018; di revisi: 20-April-2019; dipublikasikan: 28-Juni-2019)

\begin{abstract}
The final year students are in a transition period from college to work life, their personal characteristics and support from others would enhance their career adaptability. This study aimed to examine the role of contextual support for career adaptability in final year students mediated by career decision making self-efficacy (CDMSE). 270 final year students were participated in this study, obtained by using quota sampling technique which each region of JABODETABEK was represented by 30 people. Quantitative research methods applied in this study. The measuring instruments included Career Adaptability Ability Scale (CAAS), Contextual Support and Career Decision Making Self-Efficacy Scale-Social Affirements (CDMSESAF). The analysis was conducted using a mediation test and obtained results that contextual support contributed to career adaptability mediated by CDMSE ( $p<0.05$ ). In order to improve the career adaptability, the person must have a confidence in his career choices first which can be determined by the amount of contextual support that is obtained.
\end{abstract}

Keywords: Career Adaptability; CDMSE; Contextual Support; Final-year College.

Abstrak: Mahasiswa tingkat akhir berada dalam masa transisi dari dunia perkuliahan ke dunia kerja, mereka membutuhkan kemampuan personal dan dukungan dari lingkungan agar dapat beradaptasi dengan baik di dunia kerja. Penelitian ini bertujuan untuk mengetahui peranan dukungan kontekstual terhadap adaptabilitas karier pada mahasiswa tingkat akhir yang dimediatori oleh career decision making self-efficacy (CDMSE). Partisipan dalam penelitian ini diperoleh dengan menggunakan teknik kuota sampling yang berjumlah 270 mahasiswa tingkat akhir, setiap wilayah JABODETABEK diwakili oleh 30 orang. Penelitian dilakukan dengan menggunakan pendekatan kuantitatif, data dikumpulkan dengan menggunakan survey. Alat ukur yang digunakan antara lain Career Adapt-Ability Scale (CAAS), Dukungan Kontekstual dan Career Decision Making SelfEfficacy Scale-Social Affiramtion (CDMSE-SAF). Analisa dilakukan menggunakan uji mediasi dan diperoleh hasil bahwa dukungan kontekstual berperan terhadap adaptabilitas karier dengan dimediasi oleh CDMSE $(p<0,05)$. Dalam meningkatkan kemampuan adaptabilitas karier, seseorang harus memiliki keyakinan atas pilihan kariernya terlebih dahulu yang dapat ditentukan dari besarnya dukungan kontekstual yang didapat.

Kata kunci: Adaptabilitas Karier; Keyakinan Pengambilan Keputusan Karier; Dukungan Kontekstual; Mahasiswa Tingkat Akhir. 


\section{2 | Jurnal Psikologi Pendidikan \& Konseling Vol. 5 No. 1 Juni 2019}

\section{PENDAHULUAN}

Salah satu tugas perkembangan dewasa awal menurut Santrock (2002) adalah melakukan sebuah pekerjaan atau memasuki dunia karier. Mahasiswa tingkat akhir telah memasuki tahapan dewasa awal, sehingga harus mempersiapkan dirinya untuk menghadapi dunia kerja. Diketahui dunia kerja memiliki perbedaan kondisi dengan dunia perkuliahan yang dijalani, seperti ketika menjadi mahasiswa tanggung jawab hanya sebatas memperoleh nilai akademis yang baik yang mana hal ini tidak bermanfaat secara langsung pada dunia karier (Wang \& Fu, 2015).

Masa transisi dari kehidupan di universitas dan dunia kerja menjadi tantangan tersendiri bagi mahasiswa yang baru saja lulus. Mereka perlu beradaptasi dengan perbedaan budaya, perbedaan lingkungan sosial dan cara interaksi serta perbedaan tuntutan tugas (Wendlandt \& Rochlen, 2008). Menghadapi perbedaan tersebut, mahasiswa tingkat akhir perlu dipersiapkan dengan baik, terutama kemampuan untuk menyesuaikan diri di lingkungan kerja. Selain itu, terdapat fenomena lain terkait proses adaptasi dalam dunia kerja. Menteri ketenagakerjaan mengatakan pertumbuhan angkatan kerja baru rata-rata 2 juta orang per tahunnya, dan $63 \%$ diantaranya adalah orang Indonesia yang bekerja tidak sesuai dengan jurusannya (Mardiana, 2017). Kondisi ini menekankan pentingnya fleksibilitas dan kemampuan adaptasi pada angkatan kerja baru, terutama bagi mereka yang bekerja tidak sesuai dengan latar belakang pendidikan yang dimiliki. Oleh karena itu, beradaptasi dan siap dalam memasuki dunia kerja adalah hal yang penting bagi individu terutama pada mahasiswa tingkat akhir. Hal ini didukung oleh pendapat Savickas \& Porfeli (2012) yang mengatakan kemampuan penyesuaian diri yang dimiliki seseorang dapat mengantisipasi beberapa masalah yang terjadi di ketika dalam masa transisi.

Ployhart \& Bliese (2006) mengemukakan penyesuaian diri adalah perilaku atau kemampuan seseorang dalam mengatasi suatu perubahan kondisi. Perilaku adaptif seseorang dalam lingkungan kerja dapat disebut sebagai career adaptability atau adaptabilitas karier. Adaptabilitas karier dapat diartikan sebagai sumber daya yang dimiliki seseorang untuk mengantisipasi dan memecahkan masalah di lingkungan kerja yang bersifat tidak terprediksi atau sebagai kesiapan seseorang dalam menyelesaikan tugasnya, menghadapi masa peralihan pekerjaan, dan mengatasi trauma dalam pekerjaannya (Savickas \& Porfeli, 2012). Menurut Duffy (2010), memiliki kepercayaan akan kemampuan menyesuaikan diri terhadap perubahan adalah hal yang sangat dibutuhkan mahasiswa tingkat akhir, dalam hal ini adalah kemampuan adaptabilitas karier.

Adaptabilitas karier adalah hal yang penting dalam dunia pekerjaan atau dunia karier. Kemampuan beradapatasi yang baik akan meningkatkan kesempatan untuk menemukan pekerjaan yang sesuai, sehingga akan meningkatkan kesuksesan dan kesejahteraan karier seseorang (Hartung, Porfeli, \& Vondracek, 2008; Hirschi, 2009; Skorikov, 2007; Koen, Klehe, \& Van Vianen, 2012). Individu dengan adaptabilitas karier yang tinggi dapat mempersiapkan diri untuk perubahan lingkungan yang akan datang dan mengambil langkah untuk meningkatkan karier mereka di lingkungan kerja kelak (Savickas, 1997). Pendapat yang sama juga dikatakan oleh O'Connell, McNeely, dan Hall (2008) adaptabilitas karier dapat memberikan hasil yang positif dalam pekerjaan dan karier, seperti menyelesaikan tugas-tugas tepat pada waktunya.

Adaptabilitas karier merupakan bagian dari perkembangan karier seseorang (Savickas, 1997). Adaptabilitas karier dipengaruhi oleh faktor internal dan eksternal. Faktor eksternal yang dimaksud dapat berupa dukungan dari luar diri. Duffy (2010) dan Hou, Wu, dan Liu (2014) mengatakan sebagian besar peneliti berfokus pada peranan karakteristik individual dan kepribadian terhadap adaptabilitas karier, sehingga kurang berhasil mendalami efek dari faktor sosial. Berdasarkan hasil penelitiannya, Blustein (2011) menyarankan untuk penelitian selanjutnya lebih mendalami faktor sosial. Ditinjau dari teori yang dikemukakan oleh Lent, Brown, dan Hackett (2000) mengenai Social Cognitive Career Theory (SCCT), lingkungan individu menentukan aktivitas karier seseorang yang berpengaruh terhadap perkembangan kariernya (Lent et al., 2000). Selain itu, Wang dan Fu (2015) yang meneliti tentang dukungan sosial menyarankan agar penelitian berikutnya mengkhususkan variabel dukungan, yaitu dukungan kontekstual. Hal ini diperkuat dalam SCCT yang menjelaskan proses pemilihan, perkembangan karier seseorang, dan 
kemampuan beradaptasi dapat dipengaruhi oleh contextual support atau dukungan kontekstual.

Dukungan kontekstual merupakan

faktor eksternal atau lingkungan yang mempengaruhi proses peminatan akademik, menentukan pilihan karier, dan mencapai kesuksesan dalam aspek pendidikan dan pekerjaan (Lent et al., 2000). Dukungan kontekstual merupakan dukungan yang didapatkan seseorang dari lingkungan sosialnya, seperti teman, keluarga, guru, dan role model (Lent et al., 2000). Raymund dkk. (2015) mengatakan dukungan kontekstual dapat berupa saran, bantuan moral, dan bantuan keuangan. Penelitian yang dilakukan oleh Hirschi (2009) menunjukkan hasil dukungan sosial (dalam hal ini adalah dukungan kontekstual) merupakan hal yang penting untuk meningkatkan kemampuan adaptabilitas karier. Lingkungan yang mendukung dapat membantu seseorang dalam mengasah kemampuan adaptabilitas kariernya dan meningkatkan harapan masa depannya (Higgins, Dobrow, \& Roloff, 2010). Hal yang sama dikemukakan juga oleh Savickas dan Porfeli (2012) melalui penelitiannya yang mengatakan budaya dan dukungan kontekstual dapat memberikan pengaruh terhadap kemampuan seseorang untuk beradaptasi. Dalam penelitian Wang dan $\mathrm{Fu}$, (2015) menunjukkan pentingnya dukungan kontekstual dalam membantu individu untuk mengatasi keadaan yang sangat kompetitif di lingkungan karier. Dalam meningkatkan adaptabilitas karier, mahasiswa harus memperluas koneksi sosial dan mengeksplorasi dukungan sosial selama berada pada masa transisi (Wang \& Fu, 2015).

Membahas tentang dukungan kontekstual, beberapa peneliti telah mengusulkan bahwa variabel kontekstual pada perilaku karier sebaiknya dimediasi oleh selfefficacy (Parker, Bindl, \& Strauss, 2010). Pengambilan keputusan karier dan kemampuan adaptasi berfokus pada kognitif individu (salah satunya adalah self-efficacy) dan variabel kontekstual. Menurut teori sosial kognitif, penilaian self-efficacy dibentuk berdasarkan empat sumber pengalaman belajar: a) pencapaian kinerja pribadi, b) pembelajaran melalui model, c) dukungan emosional dari orang lain, dan d) dorongan verbal orang lain (Lent et al., 2000). Hal ini menjelaskan bagaimana dukungan dari orang lain dan faktor eksternal dapat meningkatkan self-efficacy seseorang.
Self-efficacy adalah hal yang dapat dikaitkan dengan penyesuaian diri dalam hal ini adalah adaptabilitas karier. Self-efficacy dapat memprediksi prestasi akademik, pilihan, dan indeks kinerja seseorang sebagai bukti seseorang telah berhasil dalam melakukan adaptabilitas karier (Rudolph, Lavigne, \& Zacher, 2017). Self-efficacy seseorang dalam proses pengambilan keputusan karier dalam kerangka teori SCCT, disebut sebagai career decision making self-efficacy yang selanjutnya akan disebut CDMSE. Betz dan Hackett, (2006) menjelaskan CDMSE mencerminkan kepercayaan diri atau keyakinan individu terhadap kemampuannya dalam menyelesaikan tugas terkait rencana kerjanya dan pengambilan keputusan. CDMSE memiliki pengaruh yang signifikan, tidak hanya terhadap proses pengambilan keputusan karier, tetapi CDMSE juga berpengaruh dalam peningkatan adaptasi seseorang (Akhtar, Sajjad, \& Khattak, 2014). Telah dibuktikan bahwa CDMSE yang tinggi berkaitan dengan bagaimana individu menampilkan performa kerja yang baik dan mendapatkan hasil-hasil positif (Flores, Ojeda, Huang, Gee, \& Lee, 2006). Dengan demikian hal ini dapat disimpulkan bahwa semakin tinggi CDMSE, memungkinkan seseorang untuk melakukan adaptasi sehingga bisa menampilkan kinerja yang baik di lingkungan kerjanya (Flores et al., 2006).

Penelitian sebelumnya telah menunjukkan dukungan dari orangtua dan guru secara positif meningkatkan CDMSE seseorang (Gushue \& Whitson, 2006). Hal ini disebabkan karena orang tua dan guru adalah sumber dari dukungan kontekstual. Misalnya, orang tua dan guru dapat memberikan dukungan berupa bantuan keuangan dan nasihat yang memfasilitasi pencapaian-pencapaian kinerja seseorang (Raymund et al., 2015). Sumber dukungan kontekstual dapat mendorong perkembangan karier seseorang melalui peningkatan keyakinan seseorang bahwa ia dapat berhasil melakukan tugas-tugas penting terkait karier.

Ketika CDMSE menjadi mediator antara dukungan kontekstual dan adaptabilitas karier dapat terlihat pada dukungan yang diberikan orang tua dapat meningkatkan keyakinan mahasiswa tingkat akhir untuk menentukan keputusan kariernya. Selain itu, guru atau dosen dapat memberikan kesempatan pada mahasiswa untuk menguasai keterampilan terkait pilihan kariernya (Raymund et al., 2015). 


\section{4 | Jurnal Psikologi Pendidikan \& Konseling Vol. 5 No. 1 Juni 2019}

Kemudian, teman sebaya juga dapat memberikan bantuan positif dalam bentuk verbal seperti dorongan yang memungkinkan seseorang agar yakin atas pengambilan keputusan yang terkait dengan kariernya. Sehingga, CDMSE mahasiswa tingkat akhir dapat ditingkatkan dari beberapa dukungan yang didapatkan dari lingkungannya. Ketika CDMSE yang dimiliki seseorang sudah cukup tinggi, maka kemampuan adaptabilitas kariernya akan tinggi pula karena mereka cenderung telah menerapkannya sebelum memasuki dunia kerja. Misalnya dengan mendalami skill terkait karier yang akan dipilihnya. Oleh karena itu, CDMSE dibuktikan dapat memediasi hubungan antara dukungan kontekstual dan adaptabilitas karier (Wang \& Fu, 2015). Hal yang sama juga dikatakan oleh Raymund dkk. (2015) pengaruh positif dari dukungan kontekstual pada adaptabilitas karier dimediasi oleh CDMSE.

Ketika memediasi dukungan kontekstual, CDMSE seseorang yang berbudaya kolektivis biasanya dibentuk berdasarkan persepsi orang lain. Dalam budaya kolektivis lebih banyak menekankan pada kelompok dan interaksi sosial yang terjadi, maka faktor sosial akan berperan penting dalam mempengaruhi CDMSE seseorang yang tengah melakukan adaptabilitas karier (Wang \& Fu, 2015).

Wang dan Fu (2015) menyarankan agar penelitian selanjutnya mengkhususkan faktor sosial yaitu dukungan kontekstual, sehingga peneliti ingin melihat peranan dukungan kontekstual terhadap adaptabilitas karier pada mahasiswa tingkat akhir dengan career decision-making self-efficacy (keyakinan dalam pengambilan keputusan karier) sebagai mediatornya. Peneliti ingin melakukan penelitian dengan tema yang sama, namun dengan faktor sosial dan pada sampel yang berbeda, yakni mahasiswa tingkat akhir di JABODETABEK. Menurut data Badan Pusat Statistik (BPS), pada tahun 2017 wilayah Jakarta (Pusat, Timur, Barat, Selatan, Utara) dan Jawa Barat berada di peringkat dua besar dengan jumlah mahasiswa terbanyak di Indonesia.

\section{METODE}

Penelitian menggunakan pendekatan kuantitatif dengan desain asosiatif. Penelitian bertujuan untuk membuktikan hipotesa mengenai peran variabel dukungan kontekstual terhadap adaptabilitas karier pada mahasiswa akhir, dengan keyakinan dalam pengambilan keputusan karier sebagai variabel moderator.

Adaptabilitas karier adalah sumber daya seseorang untuk memecahkan masalah terkait kariernya yang bersifat tidak terprediksi baik saat ini maupun di masa yang akan datang. Adaptabilitas karier diukur berdasarkan beberapa dimensi, yaitu concern, control, curiosity, dan confidence. Semakin tinggi nilai total, maka semakin tinggi adaptabilitas karier yang dirasakan seseorang, namun sebaliknya, semakin rendah nilai total, maka semakin rendah adaptabilitas karier yang dirasakan seseorang. Alat ukur CAAS terdiri dari 24 aitem, dengan lima skala likert (1-5), dengan jawaban sangat tidak kuat hingga sangat kuat. Setelah dilakukan uji coba, diketahui seluruh aitem pada alat ukur adalah aitem yang valid dan memiliki nilai reliabilitas Cronbach alpha 0.964 .

Dukungan kontekstual adalah pengaruh sosial untuk menentukan pilihan karier seseorang yang diukur melalui indikatorindikator, yaitu mendapatkan dukungan dari keluarga, teman, pendanaan, institusi pendidikan dan orang lain atau lingkungan sosial. Semakin tinggi nilai total, maka semakin tinggi dukungan kontekstual. Sebaliknya, semakin rendah nilai total, maka semakin rendah dukungan kontekstual pada individu. Dukungan kontekstual diukur menggunakan social cognitive career theory (SCCT) yang sudah diadaptasi dalam Bahasa oleh Pratiwi dan Akmal (2018). Alat ukur ini terdiri dari 15 aitem, menggunakan empat skala jawaban dari sangat tidak sesuai hingga sangat sesuai. Seluruh aitem pada alat ukur tersebut merupakan aitem yang valid dengan koefisien reliabilitas 0,859.

CDMSE adalah keyakinan individu terhadap kemampuannya dalam menyelesaikan tugas-tugas terkait karier yang diukur dari beberapa dimensi CDMSE, yaitu goal selection, occupational information, problem-solving, planning, self appraisal, dan social affirmation. Semakin tinggi nilai total, maka semakin tinggi CDMSE seseorang. Sebaliknya, semakin rendah nilai total, maka semakin rendah pula CDMSE seseorang. CDMSE diukur menggunakan career decision making self-efficacy scale-social affirmation atau disebut sebagai CDMSE-SAF yang dikembangkan oleh Arlinkasari, Rahmatika, dan Akmal (2016). Alat ukur ini terdiri dari 23 aitem dan menggunakan empat skala likert (1-4), dengan respon jawaban dari sangat tidak yakin hingga sangat yakin (Arlinkasari et al., 2016). Hasil uji coba 
menunjukkan seluruh aitem pada alat ukur ini merupakan aitem yang valid dan koefisien reliabilitas CMDSE-SAf adalah 0,894.

Paritisipan penelitian ini adalah 270 mahasiswa tingkat akhir di wilayah Jadebotabek. Sampel direkrut dengan menggunakan teknik quota sampling yaitu setiap wilayah Jadebotabek diwakili oleh 30 mahasiswa tingkat akhir.

Sebelum melakukan uji hipotesa, dilakukan uji normalitas dan linearitas data. Berdasarkan hasil pengujian, diketahui data terdistribusi normal dan memiliki hubungan yang linear. Setelah itu, dilakukan uji mediasi dengan tahapan yang sesuai dengan Barun dan Kenny (Hayes, 2009).

\section{HASIL DAN PEMBAHASAN}

Efek dukungan kontekstual pada CDMSE dan adaptabilitas karier ditemukan signifikan. Pengaruh dukungan kontekstual pada adaptabilitas karier meningkat dari 0,03 menjadi 0,68 setelah menambahkan CDMSE sebagai mediator yang menunjukkan peran mediasi adalah signifikan. Kemudian ditemukan hasil total effect dengan nilai koefisien 0,68 dan signifikansi $0,000(\mathrm{p}<0,005)$, hasil direct effect dengan nilai koefisien 0,03 dan signifikansi $0,000$ ( $\mathrm{p}<0,005)$, dan indirect effect dengan koefisien 0,65 , berikut hasil uji hipotesa penelitian dapat dilihat pada tabel 1 .

Tabel 1. Hasil Uji Mediasi

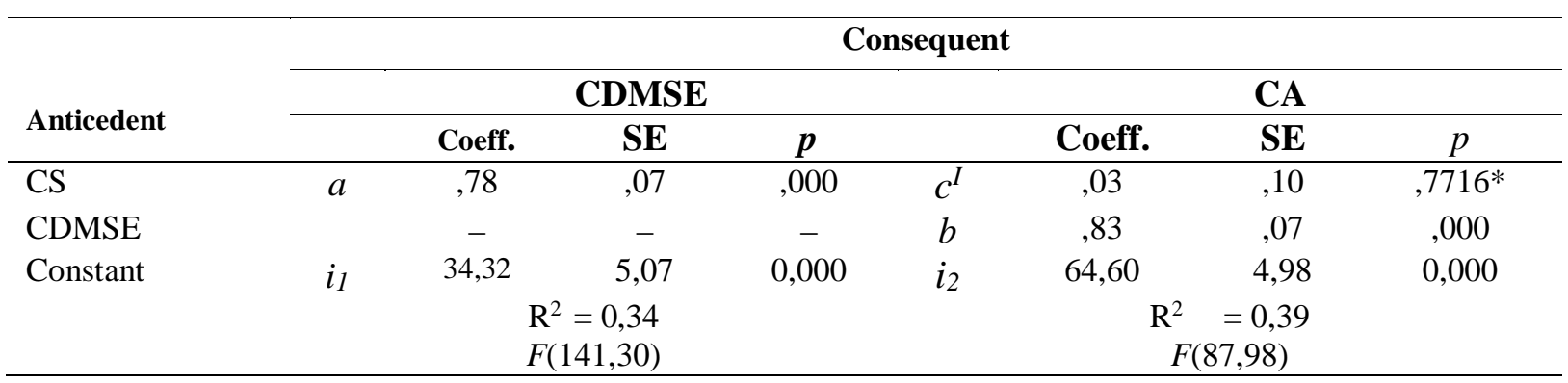

Dari hasil ini dapat diketahui bahwa dukungan kontekstual berperan terhadap adaptabilitas karier yang dimediasi oleh CDMSE. Berikut disajikan dalam gambar 1:

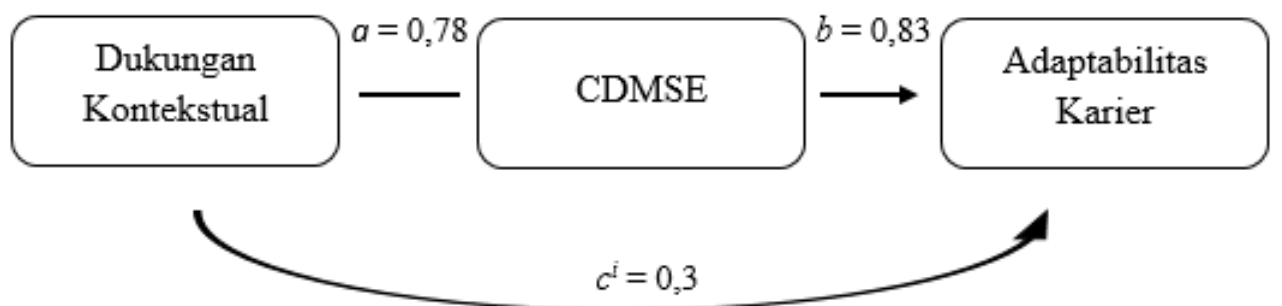

Gambar 1. Hasil Uji Mediasi

Pada penelitian ini ditemukan dukungan kontekstual memiliki peranan signifikan terhadap adaptabilitas karier mahasiswa tingkat akhir dengan nilai signifikansi $0,000(\mathrm{p}<0,05)$ dan CDMSE juga ditemukan secara signifikan menjadi mediator antara dukungan kontekstual terhadap adaptabilitas karier dengan nilai signifikansi 0,000 $(p<0,05)$. Kemudian, hasil uji hipotesis ditemukan bahwa pengaruh dukungan kontekstual pada adaptabilitas karier meningkat dari 0,03 menjadi 0,68 setelah menambahkan CDMSE sebagai mediator. Hal ini menunjukkan bahwa peran mediasi signifikan dalam men- jembatani dukungan kontekstual terhadap adaptabilitas karier. Oleh karena itu, dapat dikatakan hipotesis alternatif dalam penelitian ini diterima, yaitu dukungan kontekstual berperan terhadap adaptabilitas karier pada mahasiswa tingkat akhir dengan CDMSE sebagai mediatornya.

Sejalan dengan penelitian Wang dan $\mathrm{Fu}$ (2015), hasil penelitian ini menegaskan pentingnya dukungan kontekstual dalam membantu individu untuk menghadapi lingkungan karier yang sangat kompetitif. Ketika seseorang berada pada masa transisi dari 


\section{6 | Jurnal Psikologi Pendidikan \& Konseling Vol. 5 No. 1 Juni 2019}

masa perkuliahan ke dunia pekerjaan, para mahasiswa tahun akhir sangat membutuhkan sumber daya dukungan untuk membangun kepercayaan diri dalam menangani tugas-tugas yang terkait dengan karier yang akan datang. Dukungan yang dimaksud bisa didapatkan dari keluarga, guru, dan teman.

Ditemukan dukungan kontekstual memiliki keterkaitan dengan adaptabilitas karier seseorang. Hal ini ditunjukkan oleh individu yang berhasil melakukan adaptasi di lingkungan kerjanya cenderung memiliki relasi yang cukup lekat dengan rekan kerjanya. Dalam hal ini, artinya individu mendapatkan dukungan secara positif dari rekan kerjanya yang dapat membantunya untuk melakukan adaptasi. Selain rekan kerja, dukungan positif lain yang didapat dari keluarga, teman sebaya dan guru juga dapat meningkatkan adaptabilitas karier seseorang. Konsisten dengan penelitian Kenny dan Bledsoe (2005) yang menunjukkan dukungan yang didapatkan dari lingkungan eksternal seseorang terbukti berkorelasi positif terhadap penyesuaian diri pada para lulusan perguruan tinggi.

Sebagai variabel mediator, CDMSE dapat mendorong mahasiswa tingkat akhir untuk mengembangkan potensi adaptabilitas karier dalam pengembangan karier yang positif (Nagy, Johnston, Hirschi, Baumeler, \& Spurk, 2017). CDMSE kemudian mempengaruhi adaptabilitas karier individu karena merupakan kemampuan yang ditingkatkan untuk melakukan strategi pemecahan masalah yang efektif, mengalokasikan sumber daya, dan menetapkan tujuan yang realistis (Raymund et al., 2015). Hal ini juga sejalan dengan SCCT bahwa CDMSE memediasi faktor sosial (dalam hal ini dukungan kontekstual) terhadap pengembangan karier individu, sehingga memungkinkan individu untuk menghadapi masalah-masalah kariernya dan mampu untuk beradaptasi.

Selain itu, penelitian ini juga sejalan dengan penelitian oleh Raymund dkk., (2015) yang menemukan dukungan orang tua dan dukungan guru menonjol dalam pengembangan karier seseorang karena keduanya memberikan dukungan instrumental dan emosional. Kedua sumber dukungan ini adalah bentuk dari dukungan kontekstual. Terlebih lagi ketika dimediasi oleh CDMSE, individu dapat berhasil melakukan tugas-tugas terkait kariernya. Dukungan yang didapat individu menjadi acuan atau pegangan seseorang untuk yakin atas apa yang menjadi pilihannya dalam proses perkembangan kariernya. Orang tua dan guru yang menjadi sumber dukungan kontekstual dapat memberikan bantuan positif dalam bentuk verbal seperti dorongan yang memungkinkan individu untuk mengembangkan CDMSE-nya (Raymund et al., 2015).

Seseorang yang telah mendapatkan dukungan kontekstual yang tinggi cenderung memiliki CDMSE yang tinggi pula. Hal ini disebabkan karena tinggi atau rendahnya CDMSE seseorang ditentukan oleh besarnya dukungan kontekstual yang didapatkan. Sehingga seseorang cenderung berhasil dalam melakukan adaptabilitas kariernya. Seseorang yang berhasil melakukan adaptabilitas karier akan bisa menampilkan performa kerja yang baik di lingkungan kerjanya kelak.

Menurut SCCT terdapat faktor lain yang mungkin dapat mempengaruhi adaptabilitas karier seseorang, diantaranya goal orientation, kepribadian dan outcome expectation (Lent et al., 2000). Ketiga variabel ini diasumsikan dapat meningkatkan kemampuan adaptabilitas karier seseorang. Pendapat ini dapat dijadikan acuan untuk dilakukannya penelitian selanjutnya terkait adaptabilitas karier.

Penelitian ini fokus membahas adaptabilitas karier pada populasi mahasiswa tingkat akhir. Sementara itu, adaptabilitas karier dibutuhkan oleh individu yang berada pada masa transisi seperti fresh graduate, siswa SMK, karyawan yang akan memasuki masa pensiun. Oleh karena itu, pengembangan penelitian dapat dilakukan pada populasi tersebut. Selain itu, pada penelitian ini adaptabilitas karier yang diukur merupakan potensi kemampuan mahasiswa tingkat akhir untuk menyesuaikan diri di lingkungan kerja. Penerapan dari potensi tersebut, dapat terlihat jika mahasiswa tingkat akhir sudah memasuki dunia kerja. Dengan demikian, penelitian ini dapat dikembangkan dengan menggunakan desain longitudinal. Hal ini sependapat dengan Hirschi dan Valero (2015) yang mengatakan bahwa penelitian seanjutnya dilakukan dengan memisahkan waktu (secara periodik). Raymund dkk., (2015) juga mengatakan dukungan kontekstual dan CDMSE yang diukur pada periode waktu yang sama, tidak dapat mendapatkan hasil yang maksimal.

\section{SIMPULAN DAN SARAN}

Dukungan kontekstual berperan terhadap adaptabilitas karier pada mahasiswa tingkat akhir dengan CDMSE sebagai mediator. 
Selanjutnya untu penelitian selanjutnya diharapkan dapat (1) mengembangkan penelitian dengan menam-bahkan variabel lain, seperti goal orientation, kepribadian dan outcome expectation. (2) menambahkan variasi sampel yang berada pada tahapan perkembangan karier lain, misalnya fresh graduate, siswa SMK dan karyawan. (3) menggunakan desain longitudinal untuk mem-buktikan kemampuan adaptabilitas karier yang telah diterapkan dari masa perkuliahan sebagai mahasiswa tingkat akhir ketika telah berada pada lingkungan kerja nyata. Hasil penelitian ini dapat dijadikan sebagai acuan bagi Universitas, khususnya pusat karier dalam membantu men-gembangkan kemampuan adaptabilitas karier bagi mahasiswa tingkat akhir. Diharapkan pihak Universitas dapat (1) memberikan berbagai bentuk dukungan yang membantu meningkatkan kepercayaan diri mahasiswa tingkat akhir dalam mengambil keputusan karier seperti informasi, fasilitas, dan berbagai pelatihan terkait pembekalan menghadapi dunia kerja agar mereka lebih mudah beradaptasi ketika berada di lingkungan kerja (2) mengadakan edukasi masyarakat khususnya kepada para orangtua agar selalu memberikan dukungan bagi anaknya untuk meningkatkan kepercayaan diri anak dalam menentukan pilihan kariernya, sehingga anak mampu berperilaku adaptif dalam menghadapi masa transisi ke dunia kerja.

\section{DAFTAR RUJUKAN}

Akhtar, N., Sajjad, N., \& Khattak, S. R. (2014). Impact of Emotional Intelligence on Career Decision Making Self Efficacy among Students of Pakistani Universities. Journal of Management and Technology, 9(1), 34-48.

Arlinkasari, F., Rahmatika, R., \& Akmal, S. Z. (2016). The Development of Career Decision Making Self-Efficacy Scale ( Indonesia Version ). In International Symposium on Business and Social Science, Jeju Island, South Korea (pp. 148-158).

Betz, N. E., \& Hackett, G. (2006). Career selfefficacy theory: Back to the future. Journal of Career Assessment, 14(1), 3-11.

Blustein, D. L. (2011). A relational theory of working. Journal of Vocational Behavior, 79(1), 1-17.

Duffy, R. D. (2010). Sense of Control and Career Adaptability Among Undergraduate
Students. Journal of Career Assessment, 18(4), 420-430. Flores, L. Y., Ojeda, L., Huang, Y. P., Gee, D., \& Lee, S. (2006). The relation of acculturation, problemsolving appraisal, and career decisionmaking self-efficacy to Mexican American high school students' educational goals. Journal of Counseling Psychology, 53(2), 260-266.

Gushue, G. V., \& Whitson, M. L. (2006). The Relationship Among Support, Ethnic Identity, Career Decisin Self-Efficacy, and Outcome Expectations in African American High School Students. Journal of Career Development, 33(2), 112-124.

Hartung, P. J., Porfeli, E. J., \& Vondracek, F. W. (2008). Career Adaptability in Childhood Child Vocational Development in Context. Career Development Quarterly, 57(1), 63-74.

Hayes, A. F. (2009). Beyond Baron and Kenny: Statistical Mediation Analysis in the New Millennium. Communication Monographs, 76(4), 408-420.

Higgins, M., Dobrow, S. R., \& Roloff, K. S. (2010). Optimism and the boundaryless career: The role of developmental relationships. Journal of Organizational Behavior, 31(5), 749-769.

Hirschi, A. (2009). Career adaptability development in adolescence: Multiple predictors and effect on sense of power and life satisfaction. Journal of Vocational Behavior, 74(2), 145-155.

Hirschi, A., \& Valero, D. (2015). Career adaptability profiles and their relationship to adaptivity and adapting. Journal of Vocational Behavior, 88, 220-229.

Hou, C., Wu, L., \& Liu, Z. (2014). DECISIONMAKING SELF-EFFICACY ON CAREER ADAPTABILITY AMONG CHINESE GRADUATES, 42(6), $903-$ 912.

Kenny, M. E., \& Bledsoe, M. (2005). Contributions of the relational context to career adaptability among urban adolescents. Journal of Vocational Behavior, 66(2), 257-272.

Koen, J., Klehe, U. C., \& Van Vianen, A. E. M. (2012). Training career adaptability to facilitate a successful school-to-work transition. Journal of Vocational Behavior, 81(3), 395-408.

Lent, R. W., Brown, S. D., \& Hackett, G. (2000). Contextual Supports and Barriers 
to Career Choice: A Social Cognitive Analysis. Journal of Counseling Psychology, 47(1), 36-49.

Mardiana, C. F. (2017, August 27). No Title. Detikcom. Retrieved from https://m.detik.com/finance/beritaekonomi-bisnis/d-3620313/63-orangindonesia-bekerja-tak-sesuai-jurusan

Nagy, N., Johnston, C. S., Hirschi, A., Baumeler, F., \& Spurk, D. (2017). Assessing Key Predictors of Career Success. Journal of Career Assessment, 26(2), 338-358.

O'Connell, D. J., McNeely, E., \& Hall, D. T. (2008). Unpacking Personal Adaptibility at Work. Journal of Leadership \& Organizational Studies, 14(3), 248-259.

Parker, S. K., Bindl, U. K., \& Strauss, K. (2010). Making things happen: A model of proactive motivation. Journal of Management, 36(4), 827-856.

Ployhart, R. E., \& Bliese, P. D. (2006). Individual Adaptability (I-ADAPT) Theory: Conceptualizing the Antecedents, Consequences, and Measurement of Individual Differences in Adaptability. In Understanding Adaptability: A Prerequisite for Effective Performance within Complex Environments (6th ed., pp. 3-39). Emerald Group Publishing Limited.

Pratiwi, D. I., \& Akmal, S. Z. (2018). Peran contextual support dan barrier terhadap career indecision pada mahasiswa tingkat akhir. Jurnal Ilmiah Psikologi Terapan, 06(02), 194-206.
Raymund, P., Garcia, J. M., Lloyd, S., Restubog, D., Bordia, P., Bordia, S., ... Roxas, O. (2015). Career optimism: The roles of contextual support and career decision-making self-efficacy is.

Rudolph, C. W., Lavigne, K. N., \& Zacher, H. (2017). Career adaptability: A metaanalysis of relationships with measures of adaptivity, adapting responses, and adaptation results. Journal of Vocational Behavior.

Santrock, J. . (2002). Life Span Development (Perkembangan Masa Hidup). (J. Damanik \& A. Chusairi, Eds.) (5th ed.).

Savickas, M. L. (1997). Career adaptability: An integrative construct for life-span, lifespace theory. The Career Development Quarterly, 45(3), 247-259.

Savickas, M. L., \& Porfeli, E. J. (2012). Career Adapt-Abilities Scale: Construction, reliability, and measurement equivalence across 13 countries. Journal of Vocational Behavior, 80(3), 661-673.

Skorikov, V. (2007). Continuity in adolescent career preparation and its effects on adjustment. Journal of Vocational Behavior, 70(1), 8-24.

Wang, Z., \& Fu, Y. (2015). Social Support, Social Comparison, and Career Adaptability: a Moderated Mediation Model. Social Behavior and Personality, 43(4), 649-660.

Wendlandt, N. M., \& Rochlen, A. B. (2008). Addressing the College- to-Work Transition. Journal of Career Development, 35(2), 151-165. 